DOI https://doi.org/10.15589/znp2019.1(475).22 УДК 001.891:65.011.56

\title{
MODELS OF RECOGNITION ALGORITHMS IN THE FORM OF LOGICAL CLASSIFICATION TREES
}

\author{
МОДЕЛІ АЛГОРИТМІВ РОЗПІЗНАВАННЯ \\ У ВИГЛЯДІ ЛОГІЧНИХ ДЕРЕВ КЛАСИФІКАЦІї
}

Igor F. Povkhan

igor.povkhan@uzhnu.edu.ua

ORCID: 0000-0002-1681-3466

\section{I. Ф. Повхан}

канд. техн. наук, доцент

\author{
Uzhgorod National University, Uzhgorod \\ ДВНЗ «Ужггородський національний університет», м. Ужсгород
}

\begin{abstract}
The work raises important questions of the theory of pattern recognition, which are related to the General problem of constructing tree-like recognition schemes. It is clear that a simple, efficient, cost-effective method of constructing a logical tree of classification of the training sample allows you to provide the necessary speed, the level of complexity of the recognition scheme, which guarantees a simple and complete recognition of discrete objects. So, today there are various methods of constructing logical trees with a single use of features in the structure of a logical tree (algorithms of random trees, the method of branched collection of features with an initial assessment of informativeness), and trees with repeats of various features on the tiers of a logical tree (the algorithm of building a tree with a step-by-step assessment of the importance of features, and so on). The paper fixes the significant advantages of logical classification trees-software simplicity of building a classification tree, reducing the time of general generation of a logical tree, and so on. The work is relevant for all methods of pattern recognition in which the resulting classification function can be represented as a logical tree. In this paper, much attention is paid to the concept of a $\mathrm{T}$ - reference set, the relationship of $\mathrm{T}$-reference sets with logical classification trees is shown, and expert systems are shown in the context of recognition problems. It should be noted that the question of support sets is directly related to the question of effective search of dead-end tests, It is the question of finding the set of all dead-end tests is a computationally complex combinatorial problem, and even with modern software and hardware (even using the parallelization mechanism) cannot be solved even for relatively small training samples (several thousand objects and features). Therefore, when solving practical problems, only a certain proportion of dead-end tests are calculated and used. Representation of recognition algorithms in the form of logical trees allows to save hardware memory of the computer at their practical implementation.
\end{abstract}

Key words: pattern recognition problems; logical tree; graph-scheme models; reference sets; training sample; expert systems.

Анотація. Робота порушує важливі питання теорії розпізнавання образів, які пов'язані із загальною проблематикою побудови деревоподібних схем розпізнавання. Зрозуміло, що простий, ефективний, економний метод побудови логічного дерева класифікації навчальної вибірки дає змогу забезпечити необхідну швидкодію, рівень складності схеми розпізнавання, що гарантує проведення простого та повного розпізнавання дискретних об'єктів. Так, нині існують різноманітні методи побудови як логічних дерев з одноразовим використанням ознак у структурі логічного дерева (алгоритми випадкових дерев, метод розгалуженого вбору ознак з початковою оцінкою інформативності), так і дерев із повторами різних ознак на ярусах логічного дерева (алгоритм побудови дерева $з$ покроковою оцінкою важливості ознак тощо). У роботі фіксуються суттєві переваги логічних дерев класифікації- програмна простота побудови дерева класифікації, зменшення часу загальної генерації логічного дерева та ін. Робота актуальна для всіх методів розпізнавання образів, в яких отримана функція класифікації може бути представлена у вигляді логічного дерева. У роботі велика увага приділена поняттю Т-опорної множини, показаний зв'язок Т-опорних множин із логічними деревами класифікації, показані експертні системи в розрізі задач розпізнавання. Варто зауважити, що питання опорних множин безпосередньо пов'язане 3 питанням ефективного пошуку тупикових тестів. Саме питання пошуку множини всіх тупикових тестів обчислювано складна комбінаторна задача, яка навіть при сучасному програмно-апаратному забезпеченні (з використанням механізму розпаралелювання) не може бути вирішена навіть для порівняно невеликих навчальних вибірок (кілька тисяч об’єктів та ознак). Тому у процесі розв'язання практичних задач обчислюється та використовується лише певна частка тупикових тестів. Представлення алгоритмів розпізнавання у вигляді логічних дерев дає змогу економити апаратну пам’ять комп’ютера при їх практичній реалізації.

Ключові слова: задачі розпізнавання образів; логічне дерево; граф-схемні моделі; опорні множини; навчальна вибірка; експертні системи. 


\section{КОМП'ЮТЕРНІ НАУКИ ТА ІНФОРМАЦІЙНІ ТЕХНОЛОГІЇ №1ロ 2019}

\section{ПОСТАНОВКА ЗАДАЧІ}

Як відомо, вибір системи опорних множин видається першим і основним етапом у загальній схемі алгоритмів обчислення оцінок, детально опрацьованих ще Ю. Журавльовим, який свого часу запропонував більш загальну формалізацію з різними способами вибору інформативних підсистем ознак та формулами обчислення оцінок. Зрозуміло, що вибір системи опорних множин також визначає множину задач, для розв'язку яких можна побудувати коректний алгоритм класифікації [1]. У цьому дослідженні вводиться модифікація поняття опорної множини. Істотну роль при цьому грають логічні дерева класифікації (ЛДК) Представлення алгоритмів розпізнавання у вигляді ЛДК дає змогу економити апаратну пам'ять комп'ютера при їх практичній реалізації. Отже, постає задача розроблення ефективних методів та моделей представлення схем класифікації у вигляді логічних дерев класифікації.

\section{АНАЛІЗ ОСТАННІХ ДОСЛІДЖЕНЬ І ПУБЛІКАЦІЙ}

Аналізуючи проблематику деревоподібних моделей класифікації та розпізнавання, можна побачити певний брак досліджень у цьому напрямі, коли головна увага зміщена в бік концепції нейромережевого розпізнавання. Це дослідження продовжує цикл робіт, які присвячені методам та підходам деревоподібних схем розпізнавання (систем класифікації) дискретних об'єктів [2-8]. У них порушуються питання побудови, використання, та оптимізації логічних дерев. Так, з [3] відомо, що результуюче правило класифікації (схема), яке побудоване довільним методом або алгоритмом розгалуженого вибору ознак, має деревоподібну логічну структуру. Логічне дерево складається з вершин (ознак), які групуються по ярусах і отримані на певному кроці (етапі) побудови дерева розпізнавання [4]. Важливою задачею, яка виникає з [5], є задача синтезу дерев розпізнавання, які будуть представлятися фактично деревом (графом) алгоритмів.

\section{ВІДОКРЕМЛЕННЯ НЕ ВИРІШЕНИХ РАНІШЕ ЧАСТИН ЗАГАЛЬНОЇ ПРОБЛЕМИ}

Зважаючи на початковий аналіз поточної проблематики розпізнавання та класифікації, можна виділити проблему побудови ефективної моделі розпізнавання дискретних об’єктів (структури ЛДК). Є змога ефективної та економної роботи методу побудови структури логічного дерева на основі масиву навчальних вибірок великого об’єму.

\section{МЕТА ДОСЛІДЖЕННЯ}

Метою роботи є отримання ефективних моделей побудови логічних дерев класифікації за допомогою поняття $T$-опорної множини та можливості використання концепції логічних дерев класифікації в теорії експертних систем. Саме це дасть змогу забезпечити простий та ефективний процес розпізнавання образів, а отже, отримати найбільш адекватну та економічну форму результуючої схеми розпізнавання, що дозволить економити процесорний час на ії роботу та оперативну пам'ять для зберігання.

\section{ОСНОВНИЙ МАТЕРІАЛ}

Формальне визначення Т-опорної множини та алгоритму розпізнавання

На першому етапі цього дослідження розглянемо модель добре відомих алгоритмів розпізнавання та класифікації типу обчислення оцінок.

Нехай стоїть задача класифікації за $l$ класами об’єктів деякої множини $M \in M_{1} \cdot \ldots \cdot M_{n}$, де $M_{i}$ область ознак (метричний простір із метрикою $p_{i}$, $i=1, \ldots, n)$.

За допомогою навчаючої інформації $I(l)$, об'єкта $S$, будуються оцінки $\Gamma j(S)$, що належать $j$-вому класу, та за допомогою порогових функцій проводиться класифікація об'єкта. Кожен конкретний алгоритм класифікації $A$ в моделі визначається вибором системи опорних множин $\Omega_{A}$, функцією близькості $B(w, S, S)$, завданням ваги об'єктів за навчаючою інформацією та правилом класифікації.

Оцінки Гj(S), як правило, вираховуються за формулою:

$$
\Gamma_{j}(S)=\frac{1}{N *|W|} \sum_{S^{\prime} \in W_{j}} \gamma\left(S^{\prime}\right) \sum_{w \in \Omega \in \Omega_{A}} P(w) B\left(w, S, S^{\prime}\right) .
$$

Зауважимо, що тут $N$ - множник, що нормує; |.| - потужність (вага) деякої множини; $W_{j}$ - множина об'єктів навчаючої інформації, що належать $j$ - вому класу $(j=1, \ldots, l) ; \gamma(S)$ - деяке число, що відповідає кожному об'єкту з навчаючої інформації $I(l)$ (характеризує ступінь важливості об'єкта $S$, його інформативність); $P(w)=P_{i_{1}}+\ldots+P_{i_{k}}-$ вага опорної множини $w \leftrightarrow \Omega=\left\{i_{1}, \ldots, i_{k}\right\} ; S=\left(a_{1}, \ldots, a_{n}\right), S=\left(b_{1}, \ldots, b_{n}\right)-$ об'єкти з $M ; B(w, S, S)=1$, якщо в деякій системі нерівностей $p_{i_{1}}\left(a_{i_{1}}, b_{i_{1}}\right) \leq \varepsilon_{i_{1}}, \ldots, p_{i_{k}}\left(a_{i_{k}}, b_{i_{k}}\right) \leq \varepsilon_{i_{k}} \quad$ виконано не менше $q_{1}$ та не виконано не більше $q_{2}$ нерівностей, де $q_{1}, q_{2}$ фіксовані додатні числа та вектор $\left(\varepsilon_{1}, \ldots, \varepsilon_{n}\right)$, де $\varepsilon_{i} \leq 0, i=1, \ldots, n$ у протилежному випадку $B(w, S, S)=0$.

Перейдемо безпосередньо до головної ідеї Т-опорної множини, яка полягає у відборі та фіксації деякого набору ознак разом зі своїми значеннями.

Визначення 1. Т-опорна множина - це фіксований набір ознак із фіксованими їх значеннями:

$$
\left(\begin{array}{cc}
e_{i_{1}} & e_{i_{k}} \\
X_{i_{1}}, \ldots, & X_{i_{k}}
\end{array}\right), k=1, \ldots, n
$$

Систему Т-опорних множин будемо позначати $\Omega^{T}$. Нехай зафіксовані деякі числа $q_{1}, q_{2}$ та вектор $\left(\varepsilon_{1}, \ldots, \varepsilon_{n}\right)$, де $\varepsilon_{i} \geq 0, i=1, \ldots, n$. 
Визначення 2. Т-опорна множина

$$
\left(\begin{array}{ccc}
e_{i_{1}} & & e_{i_{k}} \\
X_{i_{1}} & , \ldots, & X_{i_{k}}
\end{array}\right)
$$

називається інформативною щодо об'єкта $S$, якщо в системі нерівностей $p_{i_{1}}\left(a_{i_{1}}, e_{i_{1}}\right) \leq \varepsilon_{i_{1}}, \ldots, p_{i_{k}}\left(a_{i_{k}}, e_{i_{k}}\right) \leq \varepsilon_{i_{k}}$ виконано не менше $q_{1}$ та не виконано не більше $q_{2}$ нерівностей.

$$
\text { Визначення 3. }\left(\begin{array}{lll}
e_{i_{1}} & e_{i_{k}} \\
X_{i_{1}} & , \ldots, & X_{i_{k}}
\end{array}\right)
$$

називається інформативною щодо класу $j$ за інформацісю $I(l)$, якщо в системі нерівностей $p_{i_{1}}\left(a_{i_{1}}, e_{i_{1}}\right) \leq \varepsilon_{i_{1}}, \ldots, p_{i_{k}}\left(a_{i_{k}}, e_{i_{k}}\right) \leq \varepsilon_{i_{k}}$ виконано не менше $q_{1}$ та не виконано не більше $q_{2}$ нерівностей, для деяких об'єктів тільки $j$ - вого класу. Стосовно об'єктів, що не входять в $I(l)$, жодних обмежень не накладається.

Введемо такі позначення: $w^{T}=\left\{w_{1}, \ldots, w_{\xi}\right\}$, де $w_{i}$ буде $i$ - вою Т-опорною множиною, $\xi$ - кількість Т-опорних множин, $H_{j}-$ множина об'єктів $S$, що належать класу $H_{j}$. Той факт, що Т-опорна множина, $w$ - інформативна до класу $H_{j}$, будемо позначати так: $w^{*} H_{j}$, аналогічно $w^{*} S-$ інформативність $w$ до об'єкта $S$. Запис $w^{*} H_{j}$ означає, що є хоча б один об'єкт $S \in H_{j}$, що $w^{*} H_{j}$.

Нехай $\Omega_{A}^{T}$ - деяка фіксована система Т-опорних множин $\Omega^{T}=\left\{w_{1}, \ldots, w_{\xi}\right\}$, яка побудована за початковою інформацією $I(l), S\left(a_{1}, \ldots, a_{n}\right)$ - деякий об'єкт iз множини об'єктів $M$. Введемо також $B(w, S)-$ функцію близькості «інформативності» об'єкта $S$ до Т-опорної множини $w$.

На наступному етапі за $\Omega_{A}^{T}$ та об'єктом $S$ будуються оцінки $\Gamma j(S)$ належності $j$ - вому класу об'єкта $S$ таким чином: $\Gamma_{j}(S)=\sum_{w \in \Omega_{A}^{T}} B(w, S)$.

Класифікація об'єкта $S$ проводиться за допомогою деякої скінчено значної функції $y=f\left(\Gamma_{j}(S)\right)$, що приймає значення $0,1, \ldots, l$. Отже, можемо зафіксувати таку модель Т - алгоритму: $\{A\}=\left(\Omega_{A}^{T}, B(w, S), \Gamma_{j}(S), y=f\left(\Gamma_{j}(S)\right)\right)$.

На відміну від відомих алгоритмів обчислення оцінок, тут центр уваги зміщений саме на вибір систем Т-опорних множин за початково ю інформацією $I(l)$. Це дає змогу зменшити час класифікації довільного об'єкта $S$ шляхом попередньої обробки масиву навчальної інформації $I(l)$ (наприклад, організація асоціативного пошуку).

Дослідження цієї моделі алгоритмів можна було би провести за традиційною схемою, але у разі практичної програмної реалізації такого підходу потрібні доволі великі затрати оперативної пам'яті комп'ютера та процесорного часу. Це дослідження спрямоване на з'ясування можливостей значного зменшення витрат апаратних ресурсів (оперативної пам'яті) при практичній реалізації алгоритмів за цією моделлю та іï̈ розширення.

Приведемо приклади деяких під-моделей введеної моделі Т-алгоритму:

$$
\begin{aligned}
& \left(\Omega_{A}^{T}, B(w, S), \Gamma_{j}(S), y=f\left(\Gamma_{j}(S)\right)\right), \text { нехай } \\
& M_{i} \in\{0,1\}, i=1, \ldots, n .
\end{aligned}
$$

На першому етапі введемо такі визначення.

Визначення 4. Т-опорна множина називається інформативною щодо об'єкта $S$, якщо відповідна комбінація ознак Т-опорної множини збігається з відповідними значеннями ознак цього об'єкта $S$.

Визначення 5. Т-опорна множина називається інформативною щодо деякого класу $j$ за початковою інформацією $I(l)$, якщо відповідна комбінація ознак (мається на увазі саме набір фіксованих ознак цієї T-опорних множин) зустрічається тільки на деяких наборах об’ єктів цього класу (тобто класу $j$ ).

На наступному етапі зафіксуємо такі функції:

$$
\begin{gathered}
B(w, S)=\left\{\begin{array}{c}
1, \text { якщо } w^{*} S \\
0, \text { упротилежномувипадку }
\end{array}\right. \\
\Gamma j(S)=\sum_{w \in \cup_{A}^{T}} B(w, S) \\
y= \begin{cases}1, & \text { якщо } \Gamma_{j}(S)>\Gamma_{i}(S), i=1, \ldots, j-1, j+1, \ldots, l \\
0, & \text { упротилежномувипадку }\end{cases}
\end{gathered}
$$

1) В якості $\Omega_{A}^{T}$ будемо вибирати тільки інформативні несуперечливі системи Т-опорних множин. Позначимо такі системи Т-опорних множин $\Omega_{A}^{T}(U, H)$, а модель:

$$
R(U, H)=\left(\Omega_{A}^{T}(U, H), B(w, S),{ }_{j}(S), y=f\left({ }^{\prime}(S)\right)\right) .
$$

Теорема 1.Немаєдеякого алгоритму $T \in R(U, H)$, який би видавав помилки на даних початкової навчальної інформації $I(l)$ та відмови класифікації на всій множині допустимих об’єктів.

Доведення. Зафіксуємо довільну систему $\Omega_{A}^{T}(U, H)$ Т-опорних множин з $\Omega_{A}^{T}(U, H)$. Візьмемо довільний об'єкт $S$ із початкової навчальної інформації $I(l)$, причому $S \in H_{j}, j=1, \ldots, l$. Тоді відповідно до визначень інформативності та несуперечливості $\Omega_{A}^{T}(U, H)$ виходить, що $w^{*} S ; \bar{\exists} i_{1} \neq i$, що $3\left(w_{i_{1}} * S \operatorname{maw}_{i} * S\right) \rightarrow\left(w_{i_{1}} * H_{j_{1}} \operatorname{maw}_{i} * H_{j}\right), j_{1} \neq j$. Отже, $j_{1}=j$, а це фактично означає, що немає довільного алгоритму $T$, який би видавав помилки на масиву початкової навчальної інформації $I(l)$. Аналогічним чином доводиться друга частина теореми.

2) Якщо як $\Omega_{A}^{T}$ вибирати тільки інформативні Tопорні множини, то системи Т-опорних множин позначаємо $\Omega_{A}^{T}(U,-)$, а модель через

$$
R(U,-)=\left(\Omega_{A}^{T}(U,-), B(w, S),{ }^{\prime}{ }_{j}(S), y=f\left({ }^{\prime}{ }_{j}(S)\right)\right) .
$$

Алгоритми цієї моделі можуть видавати помилки розпізнавання на даних початкової навчальної інфор- 


\section{КОМП'ЮТЕРНІ НАУКИ ТА ІНФОРМАЦІЙНІ ТЕХНОЛОГІЇ № 1-2019}

мації $I(l)$ та відмови класифікації на деяких допустимих об'єктах.

3) Якщо у якості $\Omega_{A}^{T}$ вибрати тільки несуперечливі Т - опорні множини, то системи Т - опорних множин позначаємо $\Omega_{A}^{T}(-, H)$, а модель відповідно через

$$
R(-, H)=\left(\Omega_{A}^{T}(-, H), B(w, S),{ }_{j}(S), y=f\left(\Gamma_{j}(S)\right)\right) .
$$

Тут також відповідно, що алгоритми цієї моделі не дають помилок розпізнавання на даних початкової навчальної інформації $I(l)$, проте дають відмови класифікації на деяких допустимих об'єктах.

4) Якщо як $\Omega_{A}^{T}$ вибрати просто довільні Т-опорні множини, то системи Т-опорних множин позначаємо $\Omega_{A}^{T}(-,-)$, а отриману модель, відповідно, через

$$
R(-,-)=\left(\Omega_{A}^{T}(-,-), B(w, S),{ }_{j}(S), y=f\left(\Gamma_{j}(S)\right)\right) .
$$

Теорема 2. Кількість всіх алгоритмів у моделі $R(-,-)$ буде дорівнювати $2^{3^{n}-1}$, де $n-$ кількість ознак у задачі розпізнавання (в описі об'єктів початкової НВ).

Доведення. При $n=1$ маємо дві Т-опорні множини:

$\left(\begin{array}{c}0 \\ X_{1}\end{array}\right),\left(\begin{array}{c}1 \\ X_{1}\end{array}\right)$. При $n=2$ маємо вісім Т-опорних множин:

$$
\begin{gathered}
\left(\begin{array}{c}
0 \\
X_{1}
\end{array}\right),\left(\begin{array}{c}
1 \\
X_{1}
\end{array}\right),\left(\begin{array}{c}
0 \\
X_{2}
\end{array}\right),\left(\begin{array}{c}
1 \\
X_{2}
\end{array}\right),\left(\begin{array}{cc}
0 & 0 \\
X_{1} & X_{2}
\end{array}\right),\left(\begin{array}{cc}
0 & 1 \\
X_{1} & X_{2}
\end{array}\right),\left(\begin{array}{cc}
1 & 0 \\
X_{1} & X_{2}
\end{array}\right), \\
\left(\begin{array}{cc}
1 & 1 \\
X_{1} & X_{2}
\end{array}\right) .
\end{gathered}
$$

При $n=k$ маємо $2^{1} c_{n}^{1}$ Т-опорних множин довжини $1,2^{2} c_{n}^{2}$ - довжини $2 \mathrm{i}$, відповідно, $2^{k} c_{n}^{k}$ - довжиною $k$. Отже, для довільного $n$ маємо $S_{n}=2^{1} c_{n}^{1}+2^{2} c_{n}^{2}+\ldots+2^{n} c_{n}^{n}$. Звідси $S_{n}=3^{n}-1$. Це кількість всіх можливих Т-опорних множин. Кількість всіх можливих систем $\Omega_{A}^{T}(-,-)$ при цьому визначається $2^{3^{n}-1}-1$.

Зазначимо, що найбільший інтерес викликають саме прості системи Т-опорних множин. Алгоритми розпізнавання, що їх визначають, не дають помилок розпізнавання на даних початкової навчальної інформації $I(l)$ та відмов класифікації на всій множині допустимих об’єктів. Крім того, як буде показано далі, складність прийняття рішень на довільно допустимому об'єкті $S$ не перевищує $n$, простих значень ознак цього об'єкта.

Теорема 3. Ємність всіх моделей $R(-,-)$, $R(-, H), R(U,-), R(U, H) \in$ скінченою.

Для доведення теореми достатньо розглянути лише модель $R(-,-)$, оскільки інші є її частиною.

Приклад. Нехай $S_{1}=(0,0,0,0), S_{2}=(1,0,1,0)$, $S_{3}=(1,1,1,1), S_{1} \in H_{1}, S_{2} \in H_{2}, S_{3} \in$ ?.

Для цього прикладу не існує $\Omega_{A}^{T}(-,-)$ щоб Т-алгоритм класифікував об'єкт $S_{3}$ як належний до класу $H_{1}$.
Наслідок. Введення різних параметрів при обчисленні оцінок $\Gamma_{j}(S)$ не розширяє моделі $R(-, H)$, $R(U, H)$.

Наведена теорема та іiї наслідок дають змогу розглядати і інші моделі. Ці моделі можна розширити шляхом запропонованих інших визначень інформативності Т-опорної множини щодо класу $j$ та об'єкта $S$. Наведемо одне 3 них.

Визначення 6. T-опорна множина $w$ називається інформативною щодо об'єкта $S$, якщо відповідна комбінація значень ознак знаходиться в деякому відношенні $\varphi$ з відповідними значеннями ознак об'єкта $S$.

Визначення 7. Т-опорна множина $w$ називається інформативною щодо класу $j$ за початковою інформацією $I(l)$, якщо існує відповідна множина деяких відношень $\varphi_{i}$, значень ознак всіх об’єктів класу $j$ з комбінацією ознак множина $w$.

Визначення 8. ЛДК - це зв'язаний граф без циклів, у некінцевих вершинах якого знаходяться ознаки (узагальнені ознаки, алгоритми, узагальнені алгоритми), а ребра нумеруються значеннями цих ознак. У кінцевих вершинах (кінцевого ярусу) ЛДК знаходяться значення функції, що задає розбиття початкової інформації на класи або символ $\Delta$ невизначеності. Причому будуть виконуватись такі умови:

а) на фіксованому шляху в ЛДК одна і та сама ознака зустрічається тільки один раз (випадок регулярного дерева);

б) об'єктам із $I(l)$ відповідає значення функції, що задає розбиття, за умови початкової відмінності між об'єктами різних класів (виконання гіпотези несуперечливості);

в) довільному об'єкту $I(l)$ відповідає одно із значень множини $\{0,1, \ldots, l\}$.

Нині є різні алгоритми та методи побудови ЛДК, що задовольняють цьому визначенню та ін. [6-8].

Визначення 9. Правилом розпізнавання (класифікації) є деякий оператор П, що приводить довільний допустимий об'єкт $S$ за його інформаційним описом $I(S)$ у кінцеву вершину ЛДК (де знаходиться значення функції розпізнавання для цього об’єкта).

Визначення 10. Деякий алгоритм Т називається алгоритмом розпізнавання (класифікації), якщо він переводить початкову інформацію $I(l)$ та інформаційний опис довільного числа $q$ допустимих об'єктів $I(q)$ у вектор $a_{r+q}$, складений з елементів $\{0,1, \ldots, l\}$, де $r=|I(l)|-$ кількість об'єктів, що становлять початкову інформацію $I(l)$, причому об'єктам із $I(l)$ відповідає значення функції, що задає розбиття, за умови початкової відмінності між об'єктами різних класів.

Очевидно, що фіксоване ЛДК, побудоване за початковою інформацією $I(l)$ із заданим правилом розпізнавання (класифікаціі), задає деякий алгоритм розпізнавання.

Теорема 4. Довільне ЛДК (за даними деякої початкової НВ) задає систему Т-опорних множин, 
причому кількість Т-опорних множин у цій системі дорівнює кількості кінцевих вершин ЛДК, а кількість інформативних Т-опорних множин щодо заданих класів дорівнює кількості визначених вершин ЛДК.

Зауваження. Під визначеною вершиною ЛДК, розуміємо вершину в якій знаходиться конкретна мітка зі значення ФР (число або константа). Тобто визначена вершина зазвичай фіналізує деякий шлях (схему розпізнавання) в ЛДК.

Наслідок. Якщо в ЛДК всі кінцеві вершини визначені, то воно задає просту систему Т-опорних множин.

Доведення. Зафіксуємо в ЛДК деяку його визначену вершину. Зрозуміло, що цій вершині відповідає цілком визначений шлях у ЛДК, що зв'язує іiі із початковою вершину ЛДК та характеризується деяким набором ознак і їх фіксованих значень. Це ніщо інше, як Т-опорна множина. Здійснимо аналогічну процедуру зі всіма кінцевими вершинами ЛДК. Очевидно, що кожна кінцева вершина в ЛДК задає деяку Т-опорну множину. Якщо кінцева вершина ЛДК визначена, то Т - опорна множина, відповідна цій вершині, буде інформативною щодо класу, номер якого знаходиться в цій вершині, бо об'єкти, що потрапляють у цю вершину, належать одному фіксованому класу.

Доведення наслідка. Всі кінцеві вершини ЛДК визначені, отже:

1) дерево визначає тільки інформативні Т-опорні множини до відповідних класів;

2) кожен клас у ЛДК характеризується, щонайменше, одною кінцевою вершиною, яка, своєю чергою, визначає інформативну Т-опорну множину щодо цього класу;

3) довільний допустимий об'єкт класифікації $S$ за допомогою деякого правила розпізнавання (класифікації) приводиться в одну 3 кінцевих вершин ЛДК, але ця кінцева вершина визначає інформативну Т-опорну множину щодо нього).

Питання експертних систем у розрізі логічних дерев класифікації

У цій частині дослідження порушимо важливе питання експертних систем у задачах розпізнавання образів.

Нехай маємо, що $H=H_{1} \cup \ldots \cup H_{l}$, де $H_{1}, \ldots, H_{l}-$ класи об'єктів (образи). $I(l)=\left\{w_{1}, \ldots, w_{m}\right\}$ - деякі об'єкти 3 множини $H$, щодо яких відома приналежність до визначених класів, причому маємо таку ситуацію: $\forall H_{j}, j=1, \ldots, l ; \exists t, t=1, \ldots, m, w_{t} \in H_{j}$.

Аналогічно, $I(g)=\left\{w_{1}, \ldots, w_{g}\right\}$ - деяка множина об'єктів із $H$, щодо яких не відома приналежність до класів. Тобто в задачі розпізнавання задана деяка НВ та необхідно провести процес класифікації невідомих об'єктів.

Отже, необхідно на основі цієї початкової інформації та деяких апріорних даних $\mu(H)$ побудувати алгоритм, який би довільний (але допустимий) об'єкт $w \in H$ за його інформаційним (ознаковим) описом $I(w)$ зарахував до визначеного класу $H_{l}$.

Зауважимо, що багато задач розпізнавання можуть бути зведені до такої постановки. Наприклад, якщо $w$ - зображення, то за допомогою деяких алгоритмів $A_{i}, i=1, \ldots, k$ будь-якому зображенню можемо поставити у відповідність його опис $I(w)$, причому тут алгоритми виступають як ознаки зображень.

Алгоритми розпізнавання будемо представляти у вигляді деревоподібних схем (тобто ЛДК).

$$
\begin{aligned}
& \text { Нехай } f \in G_{|I(l)|} \text { та } f \in G_{|I(l)|}, \text { де } \\
& \qquad f=\left\{\begin{array}{l}
f\left(a_{1}, \ldots, a_{n}\right), \text { якщо }\left(a_{1}, \ldots, a_{n}\right) \in I(l) \\
\bar{f}\left(a_{1}, \ldots, a_{n}\right), \text { якщо }\left(a_{1}, \ldots, a_{n}\right) \notin I(l)
\end{array}\right.
\end{aligned}
$$

Як відомо ще з першого розділу цього дослідження, довільну функцію $k$ - значної логіки можна представити у вигляді деякого ЛДК і, навпаки, довільному ЛДК можна поставити у відповідність функцію $k-$ значної логіки. На основі цього можна зробити такий висновок.

Теорема 5. Деяке ЛДК, що реалізує функції $\left\{f, f, \ldots, f^{\cdots l-1 \ldots}\right\} \quad$ з $G_{|I(l)|}$, утворює базис задачі $Z_{k}$ (ознаки приймають не більше як $k$ - різних значень), зауважимо, що тут $l$ - кількість класів.

Доведення. Для доведення цієї теореми на першому етапі зафіксуємо довільний набір, що не входить в $I(l)$, та покажемо, що за допомогою фіксованого ЛДК, яке реалізують функції $\left\{f, f, \ldots, f^{\cdots-l-1 \ldots}\right\}$ з $G_{|I(l)|}$, та операції $\cup$ над ЛДК можна побудувати такі дерева, які би цей набір зарахували до різних класів, тобто $\{1,2, \ldots, l\}$.

Зауважимо також, що ЛДК, які реалізують функції $\left\{f, f, \ldots, f^{\cdots l-1 \ldots}\right\}$, зараховують фіксований набір до різних класів. Це безпосередньо випливає із визначення самої функції $f$.

3 іншого боку, варто зазначити, що ЛДК, яке відповідає довільній із функцій $\left\{f, f, \ldots, f^{\ldots l-1 \ldots}\right\}$, можна поставити у відповідність повне ЛДК, яке еквівалентне цьому логічному дереву. Тоді для довільного фіксованого набору можна зробити - «фактично довільне значення» шляхом виконання однієї операції $\cup$ в кінцевій вершині з ЛДК, яке дає потрібне значення. Ця операція зводиться до звичайної заміни одного значення на інше «яке потрібне нам на цьому етапі» та має математичне обгрунтування.

Отже, «утворює базис задачі $Z_{k}$ » фактично означає, що за допомогою деякого ЛДК, яке реалізують функції $\left\{f, f, \ldots, f^{\cdots l-1 \ldots}\right\}$, та операції $\cup$ над даними ЛДК ми можемо побудувати логічне дерево, яке реалізує довільну функцію з $Z_{k}$, тобто функцію з $G_{|I(l)|}$.

Відомо, що довільному ЛДК можна поставити у відповідність повне логічне дерево класифікації (ПЛДК). Якщо як вершину піддерева вибрати кінцеву вершину ПЛДК та проводити операцію $\cup 3$ до- 


\section{КОМП'ЮТЕРНІ НАУКИ ТА ІНФОРМАЦІЙНІ ТЕХНОЛОГІЇ №1-2019}

вільним ЛДК з $G_{|I(l)|}$, то результатом буде проста заміна одного значення іншим. Це повністю доводить теорему.

Найбільш просте доведення, яке, проте, на практиці не використовується, полягає в такій схемі: ЛДК $\rightarrow$ ПЛДК $\rightarrow$ заміна значень у кінцевих вершинах довільного ЛДК.

Нехай маємо деякий колектив експертів, який представляє апріорну інформацію $U(H)$. Найбільш трудомістким процесом під час побудови експертних систем $є$ етап отримання та формалізація знань експертів про цю задачу.

Пропонується формалізований процес отримання цих знань. Тобто експертам пропонуються деякі фіксовані твердження, які сформульовані за допомогою деякого логічного дерева (ЛДК) мовою, що близька до природних програмних інваріант (IF, THEN, ELSE), які безпосередньо фіксуються структурою самого логічного дерева.

Отже, задача експертів - погодитися або ні із цим твердженням (представленим у вигляді ЛДК). Результати відповідей експертів ставляться в кінцеві вершини деякого ЛДК.

Фактично, теорема (5) говорить про те, що при виконанні доволі простих умов, що отримуються на основі інформації $I(l)$, можна побудувати довільний алгоритм розпізнавання для цієї задачі. Завдання експертів - обмежити кількість розв'язків.

Отже, $I(l), I(w)$ будемо називати первинною базою цієї задачі, $\left\{D_{1}^{E}, \ldots, D_{\eta}^{E}\right\}$ - базою знань, а $D_{j}^{E}-$ ЛДК з оцінками експертів. Тобто побудова експертної системи буде полягати в знаходженні найбільш прийнятного розв'язку задачі.

\section{ВИСНОВКИ}

Зважаючи на все вищесказане в цьому дослідженні, можна зафіксувати підсумкові пункти.

1) На відміну від алгоритмів обчислення оцінок, при роботі з Т-алгоритмом центр уваги, зміщений на вибір систем Т-опорних множин за початковою інформацією $I(l)$, дає змогу зменшити час класифікації довільного об’єкта $S$ шляхом попередньої обробки масиву начальної вибірки.

2) Формальне визначення Т-алгоритму дає змогу ввести нові означення інформативності Т-опорних множин щодо довільного об'єкта $S$ та класу $H_{j}$.

3) Важливим фактом $є$ те, що немає алгоритму довільного Т-алгоритму з моделі $R(U, H)$, який би видавав помилки на даних початкової навчальної ін- формації $I(l)$ та відмови класифікації на всій множині допустимих об'єктів.

4) Алгоритми моделі $R(U,-)$ можуть видавати помилки розпізнавання на даних початкової навчальної інформації $I(l)$ та відмови класифікації на деяких допустимих об'єктах.

5) Відповідно, алгоритми моделі $R(-, H)$ не дають помилок розпізнавання на даних початкової навчальної інформації $I(l)$, проте дають відмови класифікації на деяких допустимих об'єктах.

6) Загальна кількість всіх алгоритмів у моделі $R(-,-)$ (для довільних Т-опорних множин) буде дорівнювати $2^{3^{n}-1}$, де $n$ - кількість ознак у задачі розпізнавання (інформаційного опису об'єкту НВ).

7) Ємність всіх моделей $R(-,-), \quad R(-, H)$, $R(U,-)$ та $R(U, H)$ скінчена, це випливає 3 властивості самої моделі $R(-,-)$ оскільки всі інші є їі частиною.

8) Деяке логічне дерево, що реалізує функції $\left\{f, f, \ldots, f^{\cdots l-1 \ldots}\right\}$ з $G_{|I(l)|}$, утворює базис задачі $Z_{k}$, причому ознаки приймають не більше як $k$ - різних значень, а $l$ - кількість класів у задачі.

9) Для розв'язку задачі $Z_{2}$ - достатньо побудувати одне ЛДК $-f$, далі за допомогою алгоритму до навчання з ЛДК $-f$ будуємо ЛДК $-f$, тобто базис задачі $Z_{2}$.

10) Аналогічно, для задачі $Z_{k}$ - достатньо побудувати одне ЛДК - $f$, далі за допомогою алгоритму донавчання з ЛДК $-f$ будуємо ЛДК $-\left\{f, f, \ldots, f^{\ldots l-1 \ldots}\right\}$, тобто базис задачі $Z_{k}$.

11) Складність прийняття рішень у задачі $Z_{2}$ (незалежно від кількості класів) не перевищує $n$ бінарних порівнянь, де $n$ - кількість ознак у задачі (розмірність ознакового простору задачі).

12) Складність прийняття рішень у деякій задачі $Z_{k}$ не перевищує $(k-1) * n$ порівнянь.

13) Можливість ефективної побудови експертних систем на основі отриманих результатів.

14) Можливість ефективного використання до цього відомих алгоритмів (із різними еврістиками) при побудові нових систем (моделей) розпізнавання, класифікації, в тому числі - побудови експертних систем у розпізнаванні.

15) Порівняна простота програмної реалізації цього підходу (розв'язувались тестові задачі з 3000 бінарних ознак та 10 класами).

16) Складність побудови деякого ЛДК за початковою інформацією $I(l)$ еквівалентна числу $Q^{*}\left(n^{*} r\right)$, причому тут $r=|I(l)|$, а $Q$ - деякий коефіцієнт.

\section{REFERENCES}

[1] Zheng, Z., Kohavi, R., Mason, L. (2001). Real world performance of association rule algorithms [Associative algorithms in logical trees]. Proceedings of the Seventh ACM SIGKDD International Conference on Knowledge Discovery and Data Mining. Ed. by F. Provost, R. Srikant. P. 401-406.

[2] Vasilenko, Y. A., Vasilenko, E. Y., Povhan, I. F., Vashchuk, F. G. (2004). Conceptual basis of pattern recognition systems based on the method of branched feature selection. [General concept of logical trees]. Scientific and technical journal "European Journal of Enterprise Technologies". 7[1]. P. 13-15. 
[3] Vasilenko, Y. A., Vasilenko, E. Y., Povhan, I. F., Vashchuk, F. G. (2003). Method of branched feature selection in mathematical design of multilevel pattern recognition systems. [Methods and algorithms for constructing logical trees]. Scientific and technical journal "Artificial Intelligence”. № 7. P. 246-249.

[4] Vasilenko, Y. A., Povhan, I. F., Vashchuk, F. G. (2011). The problem of evaluation of complexity of logic trees, recognition, and a general method of optimization. [Methods of optimization of logical trees]. Scientific and technical journal "European Journal of Enterprise Technologies”. № 6/4(54). P. 24-28.

[5] Povkhan, I. F., Vashchuk, F. G. (2012). Overall assessment of minimization of logical tree structures [The problem of minimizing logical trees]. Scientific and technical journal "European Journal of Enterprise Technologies”. № 1/4(55). P. 29-33.

[6] Quinlan, J. R. (2008). Induction of Decision Trees. [General theory of logical trees]. Machine Learning. №1. P. 1-81.

[7] Vtogoff, P. E. (2009). Incremental Induction of Decision Trees. [Algorithms of decision trees]. Machine Learning. № 4. P. 161-186.

[8] Povkhan, I. F. (2018). The problem of functional evaluation of the training sample in the problems of recognition of discrete objects. [The problem of assessing the importance of features]. Scientific notes of Taurida national University. Series: technical Sciences. Volume 29(68). № 6. P. 217-222.

\section{СПИСОК ВИКОРИСТАНОЇ ЛІТЕРАТУРИ}

[1] Zheng, Z., Kohavi, R., Mason, L. (2001). Real world performance of association rule algorithms. Proceedings of the Seventh ACM SIGKDD International Conference on Knowledge Discovery and Data Mining. Ed. by F. Provost, R. Srikant. P. 401-406.

[2] Василенко, Ю. А., Василенко, Е. Ю., Ващук, Ф. Г., Повхан, І. Ф. (2004). Концептуальна основа систем розпізнавання образів на основі метода розгалуженого вибору ознак. Науково-технічний журнал "European Journal of Enterprise Technologies”. № 7[1]. C. 13-15.

[3] Василенко, Ю. А., Василенко, Е. Ю., Ващук, Ф. Г., Повхан, І. Ф. (2003). Метод розгалуженого вибору ознак в математичному конструюванні багаторівневих систем розпізнавання образів. Науково-технічний журнал «Штучний Інтелект». № 7. С. 246-249.

[4] Василенко, Ю. А., Василенко, Е. Ю., Ващук, Ф. Г., Повхан, І. Ф. (2011). Проблема оцінки складності логічних дерев розпізнавання та загальний метод їх оптимізації. Науково-технічний журнал “European Journal of Enterprise Technologies”. № 6/4(54). С. 24-28.

[5] Повхан, І. Ф., Ващук, Ф. Г. (2012). Загальна оцінка мінімізації деревоподібних логічних структур. Науково-технічний журнал "European Journal of Enterprise Technologies”. № 1/4(55). C. 29-33.

[6] Quinlan, J. R. (2008). Induction of Decision Trees. Machine Learning. № 1. P. 1-81.

[7] Vtogoff, P. E. (2009). Incremental Induction of Decision Trees. Machine Learning. № 4. P. 161-186.

[8] Повхан, І. Ф. (2018). Проблема функціональної оцінки навчальної вибірки в задачах розпізнавання дискретних об'єктів. Вчені записки Таврійського національного університету. Серія: технічні науки. Том 29(68). № 6. С. $217-222$. 